Research article

\title{
A surprising turn of events - episodes towards a renaissance of civil society infrastructure in England
}

\author{
Rob Macmillan* \\ CRESR, Sheffield Hallam University
}

\begin{abstract}
As a result of COVID-19, civil society infrastructure - the structures and systems for supporting civil society - appears to have become fashionable again after years of neglect. This article examines five recent 'episodes' which together might signal the beginnings of a surprising turn in the way civil society infrastructure in England is discussed, and its role recognised and valued. In the decade before COVID-19, a great deal of civil society infrastructure had been dismantled following disinvestment and disenchantment in policy and practice, creating a fragmented landscape of provision. During the pandemic, however, it has experienced something of a renaissance, at least in terms of national debate and developments. The article seeks to place this potential shift in historical context and begins to trace lines of connection through recent developments. It concludes by contrasting two visions for how civil society infrastructure should be organised, suggesting tentative counter-currents to a decade-long project of dis-coordinating civil society infrastructure.
\end{abstract}

Keywords: civil society; voluntary sector; infrastructure; COVID-19; collaboration.

\section{Introduction}

“...the UK does not lack volunteers or community spirit; it lacks the infrastructure to harness their potential for public benefit at a time of continuing need... We need resources for the voluntary sector yes, but more than that we need a system for making the most of those resources. It is a word we should use with pride when it comes to the voluntary sector: infrastructure."

Ed Mayo, Pilotlight, 29th June 2020 (Mayo, 2020a) 


\section{An unlikely turn of events}

When rumours of Coronavirus began to circulate in early 2020, it would have been a surprise to most people to know that within a matter of weeks an outbreak in a large country far away would wreak such global havoc - lives lost, livelihoods compromised, normal social life suspended. As a massive shock to the system, the multiple effects ripple through all aspects of society, changing just about everything, including terms of debate and public sentiment, and opening up new possibilities before the kaleidoscope settles.

The pandemic has been hugely consequential for voluntary action and broader civil society, highlighting its capacity to respond in a crisis, but also revealing its complexity, tensions and vulnerabilities. Real time commentary and emerging research documented the role and challenges for voluntary action through the crisis, in terms of resourcing, operation and demand (Macmillan, 2020) alongside complex and changing relationships with the state (Dayson and Damm, 2020). The community spirit proclaimed by the upsurge in volunteering, fundraising and neighbourly mutual aid has been almost universally applauded. The Prime Minister was moved to say it demonstrated that 'there is such a thing as society' (Williams, 2020), whilst the Chancellor of the Exchequer praised the essential 'gentleness of charities' for providing hope in the crisis (Sunak, 2020).

Warm words of political support, heightened recognition and yet ongoing vulnerability raise questions about how all this activity should best be supported, promoted and even coordinated, both through and beyond the pandemic. One of the most intractable questions here is what role the state should play, if any, in relation to civil society should civil society be left primarily to organise and support itself, underpinned by a minimally enabling policy environment, or should the state play more of an active role?

This question is directed towards the idea of civil society infrastructure, the structures and systems for supporting civil society. It may seem to be one of the more obscure and shaded niches of society, but here we encounter a paradox. Over the last ten years or so politicians, policymakers and funding organisations have been very keen to support and promote civil society and voluntary action, but decidedly reluctant to support its infrastructure. During COVID-19, however, there are tentative signs that support for infrastructure has increased. It appears that 2020 has witnessed something of a surprising rehabilitation of the idea of infrastructure, a wider recognition of its role and value, even an unlikely renaissance.

This article outlines a series of developments which together might amount to such a renaissance. It is mostly an attempt to chart what appears to have happened in discussions about civil society infrastructure during the pandemic, at least at 'national' level, in England. The article seeks to trace lines of connection through a series of events or episodes, and to begin to interpret what they might mean. The article concludes by suggesting that together these episodes point towards a counter-current to a decadelong project of dis-coordinating civil society infrastructure in England.

\section{Clearing the ground - civil society infrastructure}

The concept of 'infrastructure' is often used to refer to the cross-cutting systems of support, guidance and expertise available to ordinary civil society organisations, such as 
charities, voluntary organisations and community groups, faith groups, community business and social enterprise. Infrastructure became the favoured term-in-use during the Labour governments between 1997 and 2010, but other terms come in and out of fashion, such as 'development agencies', 'intermediary bodies' and 'umbrella bodies'. The current government appears to prefer the language of social sector 'support systems' (HM Government, 2018: 77). Latterly discussions have become somewhat muddled by the alternative framing of 'social infrastructure', usually referring to 'the physical places and organizations that shape the way people interact' (Klinenberg, 2018: 5).

A wide range of organisations can be considered to be part of civil society's infrastructure. The UK Civil Society Almanac 2020 estimated that there were around 1030 'umbrella' voluntary organisations in the UK, with an estimated combined income in 2017-18 of $£ 387.6 m$ (Hornung et al, 2020: 14). The field would include, for example, national membership bodies such as the National Council for Voluntary Organisations (NCVO) in England, and its equivalents in Wales, Scotland and Northern Ireland, countywide and local infrastructure organisations such as Rural Community Councils and Councils for Voluntary Service, and those working at neighbourhood level such as community anchor organisations. These are joined by organisations supporting and representing the sector in specific fields, such as criminal justice and children's services, or focusing on specialist areas of work, such as fundraising, governance or financial management, or supporting particular communities of interest, such as Black, Asian and Minority Ethnic organisations, or specific types of organisation, such as community businesses or small charities.

The cross-cutting work of infrastructure can be provided in many different ways, by specialist organisations in civil society for whom it is a primary purpose, by others where it is a secondary set of activities, by freelance consultants and other private sector agencies, and through other organisations such as funding bodies and statutory agencies. Given such diversity, discussion often gives priority to infrastructure functions, rather than who provides them. One useful model developed by NCVO distinguishes broadly between three types of function: 'Development', referring to direct support, facilitating learning and information, advice and guidance (where the term capacity building is often used); 'Connection', covering networking, collaboration and brokering; and 'Influence', referring to consultation, representation and promotion. Broadly speaking, external and public funding for 'Development' has been more readily available over time than for 'Connection' and 'Influence'.

An important distinction is often made between 'frontline' civil society organisations and 'second-tier' infrastructure, although the difference can be blurred in practice. A longstanding line of debate focuses on the relative priority, resources and power afforded to frontline organisations in terms of the support they need, want and can access. This has underpinned a great deal of change in the field of civil society infrastructure over the decade leading up to the pandemic in 2020.

\section{Disinvestment, disenchantment, dismantling: the unsettled state of infrastructure}

It is arguable that 'peak' civil society infrastructure, at least as characterised by significant policy attention and public investment, occurred sometime in the years between 2006 and 2009. At this time the Labour government's 10-year $£ 231 \mathrm{~m}$ 'ChangeUp' strategy to enhance infrastructure was being delivered through a dedicated agency, Capacitybuilders. This period was before the real effects of the 2008 financial crisis had become manifest, and before the change of government in the otherwise 
inconclusive 2010 general election. ChangeUp's aim was hugely ambitious, that: 'by 2014 the needs of frontline voluntary and community organisations will be met by support which is available nationwide, structured for maximum efficiency, offering excellent provision which is accessible to all while reflecting and promoting diversity, and is sustainably funded' (Home Office, 2004: 7). Announcing the strategy in parliament, the minister stressed that ChangeUp 'sets out an architecture for how ... infrastructure should develop and highlights key strategic actions that will bring it into being' (Mactaggart, 2004).

Labour's underlying approach was to build a coherent and coordinated system, an architecture of support for frontline organisations. But the programme was never completed. It was brought to a premature end by the incoming Conservative-led coalition government from 2010, an early victim of austerity-inspired public spending cuts in central government departments and through local authorities. Civil society infrastructure faced disinvestment, as funding was gradually withdrawn by successive Conservative-led governments.

But it was not only austerity that unsettled the field of civil society infrastructure. The approach and underlying assumptions also changed, and a wider disenchantment with existing infrastructure began to prevail. The Coalition advanced a 'Big Society' vision of direct grassroots local social action supplemented by new opportunities for civil society organisations to run public services. This appeared to bypass traditional organised forms of support for voluntary action, and civil society's existing infrastructure lost its relatively privileged position in policymaking. Capacitybuilders was closed down, many government-funded strategic partner relationships with national infrastructure bodies were phased out, and the government signalled a preference for market-based consultancy models for supporting frontline organisations with capacity building or 'investment readiness'.

Key funders in civil society, such as the Big Lottery Fund (now The National Lottery Community Fund), followed suit. The dominant idea was that civil society organisations should be able to choose and pay for the support and guidance they require. This led to more bespoke, 'demand-led' approaches to capacity building, such as 'funding plus' (Cairns et al, 2011) and voucher schemes, underpinned by a growing market of consultancy (Big Lottery Fund, 2012; Macmillan, 2013). Thus, during the 2010s, under the auspices of Conservative-led governments, Labour's vision or model for civil society infrastructure was dismantled.

Although transition funding was made available through programmes such as 'Transforming Local Infrastructure' and 'Big Assist', many existing infrastructure organisations struggled to adapt. Some organisations closed, whilst others merged, contracted, or tried to advance new business models based on charging for services hitherto provided free of charge. Expressing the zeitgeist, one commentator asked if it was 'the end of a long road' for Councils for Voluntary Service (Rochester, 2012). Gradually the vision of a coordinated model of support for civil society, and accompanying voice to government, was superseded by a looser, perhaps more fragmented and more competitive model of support. Mayo (2020a) concludes that 'The case for infrastructure was lost over the austerity years. Good things happened; the best of [the] network bodies adapted and new infrastructure organisations emerged...Even so, with grant funding withdrawn, the overall result was a far weaker voluntary sector, anaemic in the context of growing need... What was missing has been the core case for infrastructure'. 


\section{A new story in five episodes}

Given this background, how has the notion of civil society infrastructure appeared in commentary and discussion over the COVID-19 months of 2020-21? What impact might the pandemic have had on the terms of debate, or the broader sentiment, surrounding civil society infrastructure? This section examines five developments within and around civil society infrastructure at national level in England. These are presented as 'episodes' in what might become a new emerging story. They have been identified and collated from an ongoing process of reviewing developments and discussions around civil society during the pandemic. This involved following news items and commentary in specialist trade press; observing debates in blogs, through social media, and in COVID-19-related webinars and workshops, and noting announcements by government and key grantmaking bodies. The 'episodes' have been selected as putative 'signs of the times', particularly striking or somehow emblematic moments which seem to suggest that something might be shifting. The episodes cover three broad themes: collaboration between national infrastructure bodies (episode one); recognition and funding (episodes two, three and four); and convening spaces for dialogue and greater coordination (episode five).

\section{Episode one: Collaboration between infrastructure organisations ('Never more needed')}

On $8^{\text {th }}$ April 2020 Chancellor Rishi Sunak announced a package of $£ 750 m$ to support charities in response to Coronavirus (Sunak, 2020). It followed amplified calls for urgent targeted support for charities, organised by a coalition of mainly national infrastructure umbrella bodies, working under the banner of \#EveryDayCounts (Wilding, 2020). The funding package was met with only cautious support in the sector at the time - it was 'an important first step' but was insufficient, 'little more than a sticking plaster' (BBC News, 2020). A later reflection observed that 'This level of funding would have been unimaginable pre-pandemic and without the collaborative efforts of infrastructure organisations' (Kennedy, 2021).

In the second half of April 2020, the sector's campaign had broadened and morphed into \#NeverMoreNeeded, with a new dedicated website of news and resources. A campaign pack states that 'In the face of coronavirus, charities are \#NeverMoreNeeded - for the essential support they provide in crisis and beyond, and how they shape our society for the better... The Government cannot afford to overlook or undervalue the notfor-profit sector at the moment' (Never More Needed, 2020: 2-3).

The campaign involved civil society infrastructure bodies working together to share information, pool ideas, offer each other mutual support and discuss the impact on the charity and voluntary sector' (Walker, 2020: 1). The aim was to lobby government to recognise the value of the sector and respond with funding and support. It was likened to 'travelling together' to 'fill the gap that exists in terms of a compelling, collective voice for a sector seen perhaps as tarnished and predictable' (Mayo, 2020b).

Never More Needed has involved twice weekly meetings of a core leadership group of 15 CEOs, plus a wider group of CEOs from around 60 other civil society organisations. A series of sub-groups has examined wider issues raised during the pandemic such as regulation, contracting and commissioning, volunteering, grants and foundations and equalities. The work has involved 'Hundreds of people...in a number of different weekly coordination meetings between CEOs, policy people and comms teams' (Kennedy, 2021), and considerable effort behind the scenes to create, improve and translate guidance for the sector operating through COVID-19 restrictions. 
A review of the campaign notes the unprecedented degree of co-operation and collaboration. The core group 'first got together from a mix of luck and logic - based on existing relationships and a sense of which parts of the sector needed to be invited in. There wasn't time for careful planning or delicate diplomacy' (Walker, 2020: 6). One CEO in the core group observes that 'Collaboration is difficult and takes time. We're still getting there, especially since there hasn't been a great history of collaboration between infrastructure bodies' (Walker, 2020: 1). But another notes that after the emergency funding was announced, 'the strength of the collaboration is perhaps best shown by the fact we have invested in continuing the collaboration, responded to new and different challenges and are committed to continuing to work more closely together in the future' (Walker, 2020: 6). Work continues to influence policy and call for further financial support as the pandemic continues, for example through the \#RightNow campaign in February 2021.

The collaboration represents an attempt to build an alliance with a coordinated voice, but with evident challenges of reaching agreement across different interests, positions and approaches. There are echoes here of the 'strategic unity' seen in the 2008-09 'recession summits' jointly convened by NCVO and government as the economic downturn was gathering speed (Alcock, 2010). The differences are also worth noting. The recession summits involved the government and sector bodies jointly creating a visible plan to shape and launch a support package (eventually worth $£ 42.5 \mathrm{~m}$ ). In 2020 any work with government officials and ministers leading up to the emergency funding was ad hoc and behind the scenes. Civil society infrastructure was mobilising independently through the media, pressing the case for emergency support from outside the mainstream policymaking process.

\section{Episode two: Recognition and funding (The National Lottery Community Fund)}

In contrast to a direction of travel seen in recent years, the National Lottery Community Fund (TNLCF) appears to have recognised the strategic role and position of infrastructure, as well as its contribution during COVID-19. This is evident in three distinct ways. First, it has highlighted the central role played by, and challenges facing, local infrastructure during COVID-19. A posting on TNLCF's webpages on 'Learning and insight about COVID-19' from 12 $12^{\text {th }}$ May 2020, for example, emphasises the coordination work of national and local infrastructure:

'Using existing local infrastructure and networks to identify and support those most in need is more effective than setting up new, competing mechanisms. Local infrastructure bodies like Councils for Voluntary Service (CVS) are playing an important role in coordinating crisis support. Many have taken the lead on both recruiting and managing the huge numbers of new volunteers. They're also helping newly-formed organisations with advice, expertise and practical support' (TNLCF, 2020a).

It goes on to observe that 'Strong local partnerships and networks are a key strength in supporting communities through this crisis. Where existing relationships and connections are already in place, it's been easier to coordinate support in response to the crisis' (TNLCF, 2020a). These points are then exemplified in a subsequent case study of Voluntary Action Leeds (VAL) in TNLCF's series 'Voices from the Pandemic - Interviews from the frontline' (TNLCF, 2020b). The tone in these postings seems both supportive in recognising the role of infrastructure, and sympathetic to its challenges.

Second, as part of its own reorientation of funding and support during COVID-19, TNLCF has worked with and through a range of 'specialist partners', including national 
infrastructure organisations and specialist networks, in order to distribute targeted emergency funding to specific parts of civil society such as women's groups, social welfare legal advice organisations and groups supporting migrants and refugees. The rationale is that 'By using their collective expertise and networks, we can ensure vital support gets to even more communities' (TNLCF, 2020c). The programmes included the COVID-19 Homelessness Response Fund, delivered through the umbrella body Homeless Link, and the COVID-19 Community Led Organisations Recovery Scheme, delivered through a partnership of Power to Change, Locality, The Ubele Initiative and Social Investment Business.

Third, in November 2020 TNLCF launched a f400K 'New Infrastructure Programme' with the aim of 'Strengthening and renewing infrastructure to be fit for the future', part of the wider Digital Fund. Following a short application window it proposes to make 8 to 10 grants of up to $£ 50 \mathrm{~K}$ each to 'emerging' infrastructure organisations (to 'help strengthen efforts and build additional capacity') and 'established' infrastructure organisations (to support 'organisational redesign and renewal'), 'combined with on-site coaching and expertise provided by a Design Lab... a dedicated team which will provide expert advice and practical support' (TNLCF, 2020d).

The funding is based on an underlying set of beliefs and working assumptions: 'For grassroots, community-led and frontline organisations to be adaptive and resilient, we believe there's a need for a diverse and effective support system (infrastructure organisations). This is especially true during the COVID-19 pandemic...The programme will also stimulate a much-needed conversation around the ways infrastructure can reinvent itself for the digital age, and the kind of resource and support it needs' (TNLCF, 2020d).

\section{Episode three: Recognition and funding (The Voluntary and Community Sector Emergencies Partnership)}

In mid-July 2020 , the government announced that $£ 4.8 \mathrm{~m}$ would be given to the Voluntary and Community Sector Emergencies Partnership (VCS EP). The partnership was formed out of multiple crises in 2017, including the fire at Grenfell Tower, and aims 'to bring together local and national organisations to deliver a more coordinated response to emergencies' (VCSEP, 2020). It is co-chaired (and hosted) by the British Red Cross (BRC) and NAVCA, the National Association for Voluntary and Community Action, and also includes Volunteering Matters, Muslin Charities Forum, UK Community Foundations and St John Ambulance, among others.

The additional government funding would be drawn from the overall $£ 750 \mathrm{~m}$ package of support for charities. It would 'be used to improve coordination across the voluntary and community sector through:

- a network of regional hubs to provide additional capacity to the VCS when demand outstrips supply at a local level.

- a national cell to match and coordinate demand for volunteers across the country, and

- a new data platform that pools sector-wider understanding of unmet need across the UK and informs a more effective response to emergencies' (DCMS, 2020).

The funding has enabled the VCS EP to expand its work during the pandemic to provide additional capacity to local response efforts. It provides a wrap-around national structure to help coordinate the response to COVID-19 and to find ways to fill gaps in provision where there is not enough local capacity to provide the support. Five regional 'multi-agency cells' operate to respond to requests for support from local voluntary and 
community organisations, and a 'national volunteering cell' scrutinises overall capacity across the sector and acts as a single point of contact for the government in mobilising volunteers for national emergencies.

\section{Episode four: Recognition and funding (Lloyds Bank Foundation for England and Wales)}

Lloyds Bank Foundation (LBF) works to fund and support often small and local voluntary and community organisations working in the most deprived areas of the country and with the most marginalised communities, usually addressing complex social issues. In recent years it had widened the support available to its grantee organisations along 'funding plus' lines (Cairns et al, 2011). Since 2014 its 'Enhance' programme provides access to tailored developmental support alongside grants, in order to strengthen the effectiveness of frontline organisations. This involves commissioning, funding and delivering support from over 100 independent consultants and providers. In common with other funders it has preferred this model of support over funding infrastructure organisations directly (Lewis et al, 2018; Lloyds Bank Foundation for England and Wales, 2019).

Without abandoning this approach, in July 2020 LBF signalled new recognition of the role of infrastructure. Its CEO acknowledged the vital contribution made by infrastructure nationally and locally, but also noted the vulnerability of many infrastructure organisations: 'Our priority will always be frontline charities helping people on the ground in communities right across England and Wales. But we know charities work best in an ecosystem and charity infrastructure bodies nationally and locally are key to that' (Streets, 2020). He spoke of 'an unsung army of charitable infrastructure coordinating activity' acting locally to provide services, mobilise volunteers and link charities to statutory bodies in the emergency response. He added that 'We want to ensure that these organisations that are the backbone of support for many small and local charities are not forgotten' (Streets, 2020).

A new Infrastructure Fund approaching $£ 0.5 \mathrm{~m}$ was launched in August 2020, targeting support for local and regional infrastructure in specific geographical areas. The fund was developed to 'provide the breathing space local and regional infrastructure organisations need to develop new ways of working and to ensure that they can continue to advocate for small and local charities at this critical time' (Lloyds Bank Foundation for England and Wales, 2020). Looking ahead, LBF argues: 'We need local and regional infrastructure charities to be advocating for small and local charities to be at the heart of recovering from COVID-19 and a core part of local areas building back better' (Howe, 2020).

Fifteen unrestricted grants of around $£ 30 \mathrm{~K}$ each were awarded at the end of January 2021, for example to Black South West Network, Support Staffordshire and Voluntary Impact Northamptonshire, with additional support for organisational development and peer learning. LBF have been explicit in recognising the role of infrastructure: 'The crisis has only amplified the importance of charity infrastructure...Anyone who has an interest in charities and their ability to effect positive change cannot afford to overlook the importance of investing in infrastructure too. Charity infrastructure might not always be immediately visible, but it's charity infrastructure's ongoing work behind the scenes that enhances so much of what frontline charities can deliver' (Howe, 2020).

\section{Episode five: Convening spaces for dialogue and greater coordination}

The final episode here consists of simultaneous and overlapping conversations about how more effectively to think about and organise support for civil society. They come together as convened spaces in which a discussion about infrastructure continues and 
its future might be imagined. They can be grouped together in part because the participation appears to involve a venn diagram of overlapping membership, but also because in different ways they are seeking to coordinate aspects of an otherwise fragmented world of infrastructure and civil society support.

The recent historical context matters in making sense of these discussions. In its 2018 Civil Society Strategy the government proposed to support social sector-led efforts to create 'a robust, diverse, and effective support system', promising to 'convene key stakeholders to explore how we can collectively help to develop strong local support systems for social sector organisations' (HM Government, 2018: 78). In practice no further action has been taken to implement this commitment, although it should be noted that ministerial ownership of the strategy changed frequently as it was developed and published, and the government itself became mired in Brexit-related policy inertia, followed by COVID-19.

Independently, the beginnings of a broader conversation about organisational development in civil society appears to have gathered pace, looking at diagnostic approaches and insights from 'funding plus', bolstered by a commitment to share reflections and learning through blogs, workshops and webinars. One conversation arises through the 'Open OD' project, led by ShiftDesign, which aims 'to inspire and support radically better organisational development in the nonprofit sector' (Bazalgette, 2020). Earlier research underpinning the project 'revealed that the nonprofit sector's approach to organisational development tends to be inconsistent, intermittent, fragmented and under-resourced' (ibid.). Accordingly, the project sought to develop a set of collectively designed principles, standards and examples - 'Patterns for Change' - as a starting point for good organisational development practice, but also to address bigger questions and assumptions about civil society and how best to support it (Stanhope, 2021; Aiken, 2021).

Another example is an emerging network on pro-bono support for the third sector, convened from late Autumn 2020 by Pilotlight, Cranfield Trust and Reach Volunteering. This initiative is underpinned by a spirit of collaboration and aims to bring together 'those focused on organisational development support for the third sector, to share knowledge, test ideas and explore opportunities for collaborative action, with a specific focus on business, professional skills and third sector support' (Pilotlight, 2020).

A third set of discussions is a series of open enquiries convened by The National Lottery Community Fund unveiled in November 2020 to explore aspects of a new "civil society approach' under the proposition that 'Through our funding, community relationships, data and insights we can be a catalyst in both supporting and shaping the sector' (TNLCF, 2020e; see also Robinson, 2020). These open enquiries cover broad cross-cutting agendas such as 'Thriving and powerful communities', 'Active adaptation and resilience' and 'Equipping communities to anticipate, imagine and shape the future'. The agenda is bold, ambitious, open and future-focused, albeit sometimes oblique. A series of 'how might we...' questions are laid out to examine future possibilities under each theme: 'we will host open enquiries where with communities and wider civil society, we can sense, feel and iterate our way towards the future together. These open enquiries will explore where there is less certainty or more to discover and help hold the space for the in-betweenness' (TNLCF, 2020e).

Amongst other things, the enquiries ask questions about infrastructure, although the terminology differs. A question under 'Thriving and powerful communities', for example, asks 'How might we support more communities to have access to the networks, resources, data, skills, relationships, etc. to keep going in the long crisis?' (ibid). The enquiry for 'The everyday infrastructure we need now' focuses on the allied concept of 'social infrastructure', being 'the connective tissue of the country: the institutions and 
gathering places, and the people...who bring people together and enable the common life of a community'. Questions here include: 'How might we better understand what infrastructure communities need locally, whether it exists and if they have access to it?' and 'Is there an 'optimum' local infrastructure that best supports the sector and/or communities to thrive? And how is this affected by socioeconomic factors?' (ibid).

\section{Beyond the fragments: making sense and thinking ahead}

Rather than reviewing emerging empirical research about the role and value of different kinds of civil society infrastructure during COVID-19, the focus in this article has been on understanding the wider meaning of some key developments and discussions. Five examples or 'episodes' have been outlined, with two purposes in mind. First, to consider the extent to which each in turn appears to signal or reinforce a putative shift in thinking around civil society infrastructure. And second, to attempt to link them together into what might be or become a broader narrative. In sum, there appears to have been a surprising but subtle shift in the way civil society infrastructure in England has been presented and discussed in significant national spaces. Of course, linking them together and calling the result a tentative renaissance is itself a particular framing, a 'making sense' of a changing field, which may also serve to bolster or solidify the changes suggested.

It is worth thinking through two related implications of the episodes presented here, concerning the role of government in supporting and promoting civil society infrastructure, and within this the priority given to 'development'. The disinvestment and disenchantment noted earlier broadly started with a change of government and a change of approach, which then influenced other funding bodies. For the most part, however, central government appears to have been an 'absent presence' in the latest developments, acting in rather isolated ways to support the emergency civil society response to the pandemic. There is as yet no concerted effort by government to discuss the systems and structures involved in supporting civil society, despite earlier commitments. The review undertaken for the Prime Minister by backbench Conservative MP Danny Kruger focused mainly on sustaining the early lockdown community spirit demonstrated by mutual aid and volunteering, but it did push on the idea of infrastructure. It called for a new 'social covenant' involving 'the mutual commitment by citizens, civil society and the state, each to fulfil their discrete responsibilities and to work together for the common good of all' (Kruger, 2020: 14). The review adopted the broader and somewhat vaguer language of 'social infrastructure' as one of four 'articles' of the covenant, although this appears to include the idea of 'support for local charities' (ibid: 43). On this, the review recommends that 'Government should engage with the sector to help nurture a revived, modernised version of the [Council for Voluntary Service]. This could include full-time resources...it could also involve charities accessing advice and support from businesses, the public sector and elsewhere in civil society' (ibid: 43).

A second, more fundamental, implication of the episodes described in this article is the continuing preference for supporting the training, capacity building and development of individual civil society groups and organisations. It does not seem to extend so readily to broader support for collective organisation and representation of their interests. Put simply, the 'development' function of infrastructure remains a priority, along with 'connection' to some degree, but the 'influence' function is not seen as a priority, and is perhaps not so welcome. This argument relates to a deeper distinction in how civil society and its supporting infrastructure are imagined and approached. A long-term and perpetual struggle for ascendancy between two alternative visions for civil society can 
be discerned: between a more 'coordinated' approach on the one hand, and a more 'dispersed' and fragmented approach on the other.

The 'coordinated' vision and approach involves efforts to integrate the field; to bring elements of civil society infrastructure together towards a common purpose, potentially through organised structures and partnership arrangements amongst civil society support bodies and between these and the state. In this vision there is a clear division of labour between different kinds of infrastructure organisation, underpinned by collaborative arrangements which serve to manage and limit competition and rivalry. This kind of approach is more likely to be supported by calls for strategic investment by the state and independent funders and can be coupled with greater recognition and influence in policy-making circles.

The 'dispersed' approach involves an opposite impetus. Collaboration and partnership may still occur, but in more sporadic or bilateral ways. There are multiple purposes in play across civil society infrastructure, and competition between infrastructure organisations is encouraged, allowing market forces to determine which organisations or strategies prevail. This approach is less likely to be underpinned by strategic investment or policy recognition. Instead a laissez-faire perspective is adopted: civil society may support its infrastructure if it so chooses, but in this approach it is not particularly a responsibility of government or a matter for public policy.

Elements of both of these opposing approaches can be found in any given moment, place or context - they are presented here in stark terms to highlight their differences. At any juncture there will be complex tensions between the two. However, it is clear that through the 2010s the sway of public policy in relation to civil society infrastructure moved away from an attempted coordinated approach. Instead, an attempt to discoordinate the field has occurred. Government and other funding has been withdrawn, the very idea of 'infrastructure' appears to have fallen out of fashion, and a more fragmented and competitive space for supporting civil society has developed. It is perhaps in this light that the episodes outlined in this article need to be seen, and where on reflection they each become all the more remarkable. They suggest that the spirit of dis-coordination and fragmentation may have reached a limit, and that an alternative coordinating push may be underway.

Two contrasting interventions appear to exemplify a spirit of coordination around civil society infrastructure and signal the beginnings of a reanimated discussion of its role, organisation and future. Mayo (2020a) makes the case for collaborative infrastructure where "we invest in the horizontal (place-based) and vertical (sector-and identity-based) networks to develop common services that can sit behind the primary charities and social enterprises the UK needs'. Meanwhile, Singh (2021), referring specifically to voice and advocacy for charities, lambasts existing national umbrella bodies and leaders for failing to speak up effectively for charities, having prioritised direct support ('development') for their members, at the expense of effective lobbying ('influence') on behalf of civil society. Singh proposes a single new organisation 'out of the ashes of the old bodies, with a mandate to get things done', tasked purely with representing and advocating for the charity sector. This would appear to take coordination, here in terms of 'influence', to its furthest extreme, by collapsing all bodies into one.

Three cautionary notes to the analysis presented in this paper need to be registered. First, there is a danger of over interpretation, of overplaying both the individual points and what they might mean in combination. There is a risk that an overly 'optimistic' perspective has been presented, for those keen to see greater recognition for the role of civil society infrastructure. Although this article has drawn on a variety of sources, it is worth noting that public pronouncements of support in the midst of a crisis should perhaps be regarded with a degree of scepticism. No doubt there will have been counter 
examples, or the episodes recounted here may simply be isolated incidents rather than a fundamental shift in perspective. It is too early to tell. The tentative direction of travel may simply be a function of a crisis context, where infrastructure has been valued and gained resources for its coordinating position and capability during an emergency. It may just be a temporary re-enchantment, and infrastructure may soon revert to being taken for granted, ignored or roundly criticised in 'normal times'. Limited resources have been made available to recognise and support emergency work, but these interventions may amount only to one-off lifelines rather than the beginning of a serious examination of how to invest in civil society infrastructure as a whole.

This leads to a second point, that these developments perhaps do not really represent a turning point, since some involve pre-COVID-19 antecedents. It would be foolish, for example, to claim that collaboration between national infrastructure organisations was practically non-existent before the Never More Needed campaign. The 'CoPlunkAlity' collaboration between national infrastructure organisations Co-ops UK, Plunkett Foundation and Locality working with and supported by Power to Change clearly demonstrated its value during COVID-19, for example through the rapid mobilisation, design and distribution of the 'C-19 Emergency Trading Income Support Scheme' for community businesses, but the collaboration was originally established in 2018 (Mayo 2020b; Power to Change 2020). These examples highlight how COVID-19 has intensified collaboration, which has become more noticeable throughout the crisis.

Finally, the episodes outlined here are not the only developments underway in the broad field of infrastructure, just the more visible ones. In particular, the focus has been on national developments, rather than the myriad and varied local spaces in which infrastructure works. Different areas will have their own detailed stories to tell of whether COVID-19 has changed perspectives on the role and value of infrastructure, in what ways, and with what consequences. These are complicated, open stories, which emerge from a variety of contested understandings of infrastructure, drawing in part from the legacy and local baggage of perspectives and assumptions about whether civil society infrastructure 'round here' is any good, has shown up and has made a difference in helping to coordinate civil society responses to COVID-19.

There is no guarantee about what happens next in these discussions, no forces of history that compel the replacement of a relatively dispersed and fragmented regime of civil society infrastructure with more of a coordinated one. Re-coordinating efforts of a sort are underway, but they may be continually disrupted or frustrated by a dispersed approach. Nevertheless, the experience of the pandemic has created the conditions for a re-animated debate about how best to support civil society.

\section{Acknowledgements}

Many thanks are due to the following for ever helpful comments and suggestions on an earlier version of this article: Joe Cook, Jane Cullingworth, Ben Hughes, Beth Longstaff, Steven Marwick, Ed Mayo, Amy Sanders, Christala Sophocleous, Janet Thorne and Karl Wilding. Thank you also to the reviewers and editors for constructive feedback and guidance on ways to strengthen the article.

*Correspondence address: Dr Rob Macmillan, CRESR, Sheffield Hallam University, Howard Street. Sheffield, S1 1WB. Email: r.macmillan@shu.ac.uk 


\section{References}

Aiken, M. (2021) Sowing seeds for organisational development in the nonprofit sector. Medium, $8^{\text {th }}$ February 2021. Available at: https://medium.com/openod/sowingseeds-for-organisational-development-in-the-nonprofit-sector-a349ccf57823 [Accessed: 09/02/21].

Alcock, P. (2010) A strategic unity: defining the third sector in the UK. Voluntary Sector Review, 1, 1, 5-24.

Bazalgette, E. (2020) Exploring radically better organisational development. Medium, $28^{\text {th }}$ September 2020. Available at: https://medium.com/openod/exploringradically-better-organisational-development-1f14139829f3 [Accessed: 13/02/21].

BBC News (2020) Coronavirus: Government funding 'not enough' to keep some charities afloat. BBC News, 9th April 2020, https://www.bbc.co.uk/news/uk52228161 [Accessed: 10/02/21].

Big Lottery Fund (2012) Building capabilities for Impact and Legacy. London: Big Lottery Fund.

Dayson, C. and Damm, C. (2020) Re-making state-civil society relationships during the COVID 19 pandemic? An English perspective. People, Place and Policy, 14, 3, 282-289.

DCMS (2020) Community Match Challenge and Voluntary and Community Sector Emergencies Partnership. Department for Digital, Culture, Media and Sport, $18^{\text {th }}$ July 2020. Available at: https://www.gov.uk/government/publications/community-match-challenge-andvoluntary-and-community-sector-emergencies-partnership [Accessed: 08/12/20].

Cairns, B., Burkeman, S., Harker, A. and Buckley, E. (2011) Beyond money: A study of funding plus in the UK. London: Institute for Voluntary Action Research.

HM Government (2018) Civil Society Strategy: building a future that works for everyone. London: Cabinet Office.

Home Office (2004) ChangeUp: Capacity Building and Infrastructure Framework. London: Home Office.

Hornung, L., Chan, O., Jochum, V., Lawson, M., McGarvey, A. and Rooney, K. (2020) The UK Civil Society Almanac 2020. London: NCVO.

Howe, C. (2020) Lloyds Bank Foundation launch new national Infrastructure Fund. Lloyds Bank Foundation, 24th August 2020. Available at: https://www.lloydsbankfoundation.org.uk/our-impact/news-and-blogs/ourinfrastructure-funding [Accessed: 06/12/20].

Kennedy, J. (2021) Elaborating on collaborating. DSC, $5^{\text {th }}$ February 2021. Available at: https://www.dsc.org.uk/content/elaborating-on-collaborating/ [Accessed: 06/02/21].

Klinenberg, E. (2018) Palaces for the People: How to Build a More Equal and United Society. London: Bodley Head.

Kruger, D. (2020) Levelling up our communities: proposals for a new social covenant. A report for government by Danny Kruger MP, 24th September 2020. Available at: https://www.dannykruger.org.uk/communities-report [Accessed: 24/09/20].

Lewis, M., Hennessey, C. and Baker, L. (2019) The impact of Enhance: Review for Lloyds Bank Foundation for England and Wales. London: Institute for Voluntary Action Research.

Lloyds Bank Foundation for England and Wales (2019) Five Years of Funder Plus. London: Lloyds Bank Foundation for England and Wales.

Lloyds Bank Foundation for England and Wales (2020) Infrastructure Fund. Lloyds Bank Foundation, 24th August 2020. Available at: https://www.lloydsbankfoundation.org.uk/covid-19/infrastructure-fund [Accessed: 06/12/20]. 
Macmillan, R. (2013) Demand-led capacity building, the Big Lottery Fund and marketmaking in third sector support services. Voluntary Sector Review, 4, 3, 385-394.

Macmillan, R. (2020) Somewhere over the rainbow - third sector research in and beyond coronavirus. Voluntary Sector Review, 11, 2, 129-136.

Mactaggart, F. (2004) Change Up: A Capacity Building And Infrastructure Framework. Written Statement by The Parliamentary Under-Secretary of State for the Home Department (Fiona Mactaggart), HC Deb, 24 June 2004, Volume 422, c85WS.

Mayo, E. (2020a) It is a word that government and funders have avoided for years infrastructure. Civil Society, 29th June 2020. Available at: https://www.civilsociety.co.uk/voices/ed-mayo-it-is-a-word-that-government-andfunders-have-avoided-for-year-infrastructure.html [Accessed: 08/07/20].

Mayo, E. (2020b) Will we travel together? ACEVO, $8^{\text {th }}$ July 2020. Available at: https://www.acevo.org.uk/2020/07/will-we-travel-together/ [Accessed: 10/02/21].

Never More Needed (2020) \#Never More Needed Campaign Pack, Edition 1, August 2020. Available at: https://nmn.org.uk/information/2020/09/NeverMoreNeeded-Campaign-Pack4.pdf [Accessed: 10/02/21].

Pilotlight (2020) Roundtable on business, professional skills and third sector support. Report on an event co-organised by Cranfield Trust, Pilotlight and REACH, November 2020, unpublished report.

Power to Change (2020) The C-19 Emergency Trading Income Support Scheme: Guidelines for applicants. London: Power to Change.

Robinson, C. (2020) Our Civil Society Approach - strengthening communities and the organisations that support them. Medium, 13 ${ }^{\text {th }}$ November 2020 . Available at: https://cassierobinson.medium.com/our-civil-society-approach-strengtheningcommunities-and-the-organisations-that-support-them-d44f5d5b2ec7 [Accessed: 12/02/21].

Rochester, C. (2012) Councils for Voluntary Service: the end of a long road? Voluntary Sector Review, 3, 1, 103-10.

Singh, A. (2021) Umbrella hell - the charity infrastructure system is designed wrong. Civil Society, 29th January 2021. Available at: https://www.civilsociety.co.uk/voices/asheem-singh-charity-advocates-need-torelearn-the-art-of-getting-peoples-backs-up.html [Accessed: 01/02/21].

Stanhope, N. (2021) Patterns for Change: a small part of a big transition. Medium, $2^{\text {nd }}$ May 2021. Available at: https://medium.com/patternsforchange/patterns-forchange-a-small-part-of-a-big-transition-8022115e59dc [Accessed: 30/07/21].

Streets, P. (2020) Our thinking and approach during COVID-19. Lloyds Bank Foundation, 30th July 2020. Available at: https://www.lloydsbankfoundation.org.uk/our-impact/news-and-blogs/paulstreets-supporting-charities-covid19 [Accessed 06/12/20].

Sunak, R. (2020) Chancellor of the Exchequer, Rishi Sunak on economic support for the charity sector, $8^{\text {th }}$ April 2020 . Available at: www.gov.uk/government/speeches/chancellor-of-the-exchequer-rishi-sunak-oneconomic-support-for-the-charity-sector [Accessed: 25/04/20].

The National Lottery Community Fund (TNLCF) (2020a) Community infrastructure, $12^{\text {th }}$ May 2020. Available at: https://www.tnlcommunityfund.org.uk/insights/covid-19resources/responding-to-covid-19/community-infrastructure [Accessed: 10/02/21].

The National Lottery Community Fund (TNLCF) (2020b) Voices From the Pandemic: Interviews from the frontline - Voluntary Action Leeds. 29th September 2020. Available at: https://www.tnlcommunityfund.org.uk/insights/covid-19resources/responding-to-covid-19/voices-from-the-pandemic-interviews-from-thefrontline/voluntary-action-leeds [Accessed: 10/02/21]. 
The National Lottery Community Fund (TNLCF) (2020c) COVID-19 Community-led Organisations Recovery Scheme. Available at:

https://www.tnlcommunityfund.org.uk/funding/programmes/covid-19community-led-organisations-recovery-scheme [Accessed: 10/02/21].

The National Lottery Community Fund (TNLCF) (2020d) The New Infrastructure Programme. Available at: https://www.tnlcommunityfund.org.uk/funding/programmes/new-infrastructureprogramme [Accessed: 04/12/20].

The National Lottery Community Fund (TNLCF) (2020e) Civil Society Approach. Available at: https://www.tnlcommunityfund.org.uk/insights/civil-societyapproach [Accessed: 04/12/20].

Voluntary and Community Sector Emergencies Partnership (VCSEP) (2020) About us. Available at: https://vcsep.org.uk/about-us [Accessed: 18/02/21].

Walker, P. (2020) Top tips for working in partnership from the collaboration of infrastructure organisations. Never More Needed, $27^{\text {th }}$ November 2020. Available at: https://nmn.org.uk/2020/11/27/lessons-from-collaborating/ [Accessed: $08 / 12 / 20]$.

Wilding, K. (2020) 'Every day counts' as charities still wait for government support. NCVO, $20^{\text {th }}$ March 2020. Available at: https://www.ncvo.org.uk/about-us/mediacentre/press-releases/2748-every-day-counts-as-charities-still-wait-forgovernment-support [Accessed: 10/02/21].

Williams, B. (2020) Why it matters that Boris Johnson thinks 'there is such a thing as society.' The Conversation, $30^{\text {th }}$ March 2020. Available at: https://theconversation.com/why-it-matters-that-boris-johnson-thinks-there-issuch-a-thing-as-society-135103 [Accessed: 21/01/21]. 